\title{
A POLÍTICA EXTERNA BRASILEIRA PARA O MEIO AMBIENTE:
}

\author{
DE ESTOCOLMO A JOANESBURGO
}

Joan Frederick Baudet Ferreira França ${ }^{1}$

\begin{abstract}
Resumo
Em 1972, a comunidade internacional não compreendeu a atitude do governo brasileiro na Conferência de Estocolmo e, por conseguinte, passou a rotulá-lo de irresponsável, ao que se reagiu com discurso combativo. Na Conferência do Rio, foi possível observar um progressivo deslocamento qualitativo do contrato social entre o Brasil e os países desenvolvidos, uma vez que, ao invés das acusações mútuas, procurou-se repartir as responsabilidades. Em Joanesburgo, o país já despontaria como ator proativo e engajado em um contexto no qual as negociações eram percebidas como suscetíveis de oferecer ganhos reais à nação. À luz do pensamento de Fierke, pode-se propor que desenvolvimento sustentável é o nome do "jogo" que soube compatibilizar as reivindicações dos distintos atores sociais, gerando nova agenda ambiental internacional.
\end{abstract}

Palavras-Chave: Política Externa Brasileira; Meio Ambiente; Conferência de Estocolmo; Conferência do Rio de Janeiro; Cúpula de Joanesburgo.

\begin{abstract}
In 1972, the international community did not understand Brazilian government's position at the Stockholm Summit and, consequently, started to call it as irresponsible. Brazil responded with a tough talk. At the Rio Summit, a progressively qualitative shift in the social contract between Brazil and the developed countries could be noticed. Once rather than mutual accusations, shared responsibilities were pursued. In Johannesburg, the country already stood out as a proactive and engaged actor in a context in which negotiations were perceived as capable of offering the nation real gains. In the light of Fierke's thought, it might be suggested that sustainable development is the name of the "game" that paved the way for coexistance between the claims of the different social actors, laying out a new international environmental
\end{abstract}

\footnotetext{
${ }^{1}$ Joan Frederick Baudet Ferreira França é estudante do curso de Graduação em Relações Internacionais da PUC-Rio.
} 
agenda.

Keywords: Brazilian Foreign Policy; Environment; Stockholm Summit; Rio Summit; Johannesburg Summit.

\section{Introdução}

Com o ingresso no século XXI, conquanto as inovações tecnológicas alcancem alto grau de sofisticação, a humanidade defronta-se com desafios desproporcionais a quaisquer outros, por ventura vivenciados até então em sua trajetória. Amplamente midiatizados pelos veículos da globalização, o aquecimento global e o desmatamento das florestas tropicais concentram as atenções do grande público acerca dos impactos ambientais em curso causados pela ação antrópica. Se por um lado, o tratamento do tema em larga escala apresenta o benefício de conscientizar um maior número de pessoas no tocante aos problemas ambientais, por outro, o mesmo acarreta uma abordagem massificada, chegando até mesmo à construção de mitos e enganos. Nesse contexto, tornam-se de suma importância estudos com respeito à temática ambiental, que possam oferecer à comunidade interessada rigor acadêmico, seja para corroborar o que é difundido em grande escala, seja para desmistificá-lo.

Segundo Roberto Guimarães, a questão ambiental representa a sobrevida de um modelo de desenvolvimento que "se mostrou ecologicamente predatório, socialmente perverso e politicamente injusto" (Guimarães, 1994, p. 202). Embora ciente de que o meio ambiente é tema intrinsecamente multidisciplinar, o presente artigo procurará tratar do que diz respeito à interação da temática ambiental com a política, mais especificamente com a política internacional. 0 recorte do objeto de estudo em interesse justifica-se pelo fato de perceber-se como tanto os impasses quanto as soluções relativas ao meio ambiente, acabam, em última instância, alocando-se no domínio da vontade política (Guimarães, 1994, p. 203).

Assim, dentro do tema da política ambiental internacional, privilegiar- 
se-á o estudo da política externa brasileira entre os anos de 1972 e 2002, período situado entre as reuniões sobre meio ambiente realizadas, em Estocolmo e em Joanesburgo respectivamente, no âmbito das Nações Unidas. Dentro desse marco temporal, espera-se verificar a ocorrência de uma mudança paradigmática no posicionamento da diplomacia brasileira frente aos desafios impostos pela agenda ambiental internacional.

Para checar a incidência do fato supracitado, pretende-se, portanto, fundamentá-lo com análise da transformação do discurso diplomático do Brasil nos foros multilaterais corporificados no seio das Nações Unidas. Assim, buscar-se-á entender como se passou, de uma posição soberanista e defensiva quando da reunião de Estocolmo, em 1972; a outra, globalista e participativa no encontro de Joanesburgo, em 2002. Espera-se demonstrar como a mudança em questão ocorreu concomitantemente à abertura do sistema político brasileiro, o qual experimentou um processo de democratização, desde a abertura "lenta, gradual e controlada" de Geisel, passando pelo fim do regime militar em 1985, até culminar na realização das eleições diretas para presidente em 1989 e nos subsequentes ajustes institucionais exigidos pelo sistema democrático.

Presume-se, pois, que o processo de democratização da sociedade brasileira permitiu crescente permeabilidade do governo - e de sua política externa - às pressões advindas do movimento ambientalista nacional e dos governos dos países desenvolvidos, sendo a análise desse último ator privilegiada pelo foco do trabalho em questão. Desse modo, tal como sugere o Embaixador Gelson Fonseca Jr., acredita-se que a mudança de paradigma da diplomacia brasileira para o meio ambiente tenha ocorrido na esteira de um processo de "renovação de credenciais" do país perante a comunidade internacional, visando retomar a legitimidade que passaria a lhe conferir o regime democrático (Fonseca, 1998).

Depreende-se que o trabalho em questão pretende deter-se em um período de inflexão da política externa brasileira. Ora, constatando-se o 
desconforto das teorias positivistas em explicar eventuais mudanças no sistema internacional, o embasamento teórico a ser adotado neste estudo apoia-se em uma epistemologia pós-positivista, a saber, na perspectiva construtivista cunhada por Karin M. Fierke em sua análise dos discursos políticos.

Ao invés de se coletar dados empíricos para confrontá-los com uma teoria previamente formulada, como fariam os positivistas, Fierke propõe que se busque compreender quais são as estruturas de significados intersubjetivos nas quais se situam as ações e práticas a serem interpretadas. As ações políticas, pois, devem ser entendidas dentro de um largo contexto intersubjetivo que constrange as escolhas dos atores; ou ainda, segundo a autora, qual um "jogo" em que há, entre outros, regras, interesses, custos de ação/inação e objetivos que permeiam a interação entre os atores (Fierke, 2001). Logo, a ocorrência de mudanças na política externa de um ator pode ser compreendida tal como a passagem de um "jogo" a outro. ${ }^{2}$

A hipótese a ser verificada, no caso, consiste em analisar se, entre 1972 e 2002, o processo de democratização da sociedade brasileira permitiu uma mudança do "jogo" contextual no qual, em decorrência de alteração das "regras" do "jogo", foi possível estabelecer um novo diálogo entre o governo brasileiro e os países desenvolvidos, um novo contrato social uma nova agenda ambiental internacional.

\section{Uma política externa na defensiva em Estocolmo}

Em 1968, é organizado em Paris o primeiro evento sobre meio ambiente sob a égide da Organização das Nações Unidas (ONU), mais precisamente sob a responsabilidade da Organização das Nações Unidas para a Educação, a Ciência e a Cultura (UNESCO). A Conferência da Biosfera teve um caráter basicamente científico e gerou diagnóstico e prognóstico bastante pessimistas para o planeta Terra.

\footnotetext{
${ }^{2}$ Há de se atentar de que não existe aqui qualquer relação às teorias de jogos racionalistas, das quais o do dilema do prisioneiro seria um exemplo.
} 
Já em 1972, a poucos meses da abertura da Conferência de Estocolmo, publicou-se, sob os auspícios do Clube de Roma ${ }^{3}$, o livro The Limits to Growth, documento que apresentava previsões baseadas em modelos computacionais de autodestruição da humanidade, caso se prolongasse o paradigma de desenvolvimento então vigente. Logo, é nesse contexto de pessimismo quase apocalíptico que uma corrente do movimento ecológico que interpretava o desenvolvimento dos países pobres como uma ameaça para o planeta fez-se atuante na capital sueca (Corrêa do Lago, 2007, p. 29-30).

Nesse cenário, uma tríade de países em desenvolvimento preocupava em especial os países desenvolvidos, em decorrência de índices excepcionais de crescimento industrial e populacional: Brasil, China e Índia (Duarte, 2003, p. 12-13).

À época da realização da Conferência de Estocolmo, o Brasil figurava entre os países em desenvolvimento vivendo sob regimes autoritários legitimados por altas taxas de crescimento econômico. Em 1972, em pleno auge do milagre brasileiro, o Produto Interno Bruto (PIB) do país crescia $11,9 \%$, período igualmente correspondente ao de maior repressão política em sua história. Sob a presidência de Emílio Garrastazú Médici, general da linha-dura do regime brasileiro e ex-chefe do Serviço Nacional de Informações (SNI), inaugurou-se a diplomacia do interesse nacional de modo a coadunar-se com o projeto aventado de Brasil potência.

Assim, mantendo-se coerente com o discurso de potência ascendente ventilado pelo governo brasileiro, a política externa desse período procurou, em certa medida, afastar o país da identidade terceiromundista, definida pelo então chanceler brasileiro, Mário Gibson

${ }^{3}$ O Clube de Roma é um think tank internacional, reunindo, entre outros, cientistas, empresários e economistas, e cujo objetivo principal consiste em propor soluções para os desafios advindos das questões ambientais. Fundado em 1968, foi idealizado pelo italiano Aurelio Peccei, então membro do conselho administrativo da empresa automotiva FIAT, e pelo escocês Alexander King, cientista e ex-diretor científico da Organização para a Cooperação e o Desenvolvimento Econômico (OCDE). Informações disponíveis em: http://www.clubofrome.org 
Barboza, tão somente como uma "concepção ilusória", ou ainda, "um mito da sub-história” (Vizentini, 1998, p. 137).

Apesar do pretenso afastamento e, ainda que se possa alegar que em Estocolmo o país tenha se posicionado exclusivamente conforme seus interesses, difícil seria negar a retórica reivindicatória adotada durante a Conferência pela diplomacia brasileira. Do mesmo modo, evidenciarse-ia, no decorrer do encontro, a articulação defensiva de países periféricos instrumentalizada pelo Brasil em nome da defesa do direito ao desenvolvimento.

As pressões ambientalistas advindas dos países desenvolvidos eram então interpretadas pela chancelaria brasileira como um domínio adicional do "congelamento do poder" imposto pelo Tratado de NãoProliferação nuclear, tal como descrito pelo Embaixador Araújo Castro, para quem a restrição do acesso à tecnologia nuclear somente àqueles que já a possuíam representava uma tentativa de perenizar uma situação de desequilíbrio de poder, calcado na divisão do mundo entre as duas superpotências da Guerra Fria. Assim, o coro ambientalista seria, na visão da diplomacia brasileira, nada mais que um "desestímulo a um rápido processo de industrialização", almejando complementar a vigência do statu quo do sistema internacional (Duarte, 2003, p. 117; 143).

Ademais, além da inconveniência da associação do ambientalismo a teses zeristas, para as quais, frente às ameaças ecológicas decorrentes de um eventual desenvolvimento dos países periféricos, se deveria parar de buscar o crescimento econômico e administrar as riquezas já produzidas, o regime militar temia o movimento ambientalista por aproximá-lo dos movimentos de esquerda (Corrêa do Lago, 2007, p. 115).

Assim, desde a Primeira Sessão do Comitê Preparatório para a Conferência de Estocolmo, realizada em Nova Iorque no ano de 1970, o chefe da Delegação brasileira, o próprio Embaixador Araújo Castro, já norteava o discurso diplomático para o que se tornaria a posição 
brasileira na Conferência. Como esclarece a Embaixadora Vera Pedrosa,

Obrava a Delegação brasileira no sentido de reorientar os trabalhos preparatórios da Conferência, ampliando o escopo inicialmente previsto, de forma a que se incluísse o tema do desenvolvimento como elemento positivo de solução de problemas ambientais. (Pedrosa apud Corrêa do Lago, 2007, p. 120)

Com efeito, os bem-sucedidos esforços brasileiros de redirecionar a tônica das negociações que ocorreriam em Estocolmo foram relatados, ainda em 1970, no Telegrama confidencial 1552 da Missão em Nova Iorque:

causou descontentamento em certos meios, pois os elementos introduzidos, por iniciativa do Brasil, [...] tendem a transformar em um movimento claramente reivindicatório o que antes parecia destinado a constituir apenas uma consagração do statu quo e do 'gap' econômico entre países desenvolvidos e nações em desenvolvimento. ${ }^{4}$

Na década de 1970, o ponto mais sensível para os interesses brasileiros durante o Comitê Preparatório, no entanto, não adviria das relações com os países desenvolvidos mas, sim, do relacionamento com a Argentina cujo posicionamento, quanto ao aproveitamento do potencial hidrelétrico do Rio Paraná, ia de encontro às intenções do governo brasileiro de construir a maior usina hidrelétrica do mundo naquela época (Corrêa do Lago, 2007, p. 118). Os argentinos queriam que fosse incluída cláusula de notificação prévia no Princípio 20, que tratava sobre notificação acerca de riscos ambientais fora da jurisdição de um Estado. Segundo Corrêa do Lago, a reivindicação argentina consistia em que Estados à montante de rios internacionais deveriam notificar dentro de um tempo hábil que possibilitasse exame e eventuais verificações - Estados à jusante acerca das ações que pretenderiam executar no curso do rio. Como o Brasil estava desenvolvendo junto ao

${ }^{4}$ Telegrama 1552 da Missão em Nova York, confidencial. Apud Corrêa do Lago, 2007, p. 125. 
Paraguai o projeto estratégico de Itaipu, visto com desconfianças por Buenos Aires, a proposta argentina era, para o Itamaraty, simplesmente "inaceitável". Ao final, o Brasil logrou sucesso nas negociações do Comitê Preparatório e o texto da Declaração foi aprovado, sem a inclusão da cláusula de notificação prévia, por todos os membros - à exceção da Argentina (Corrêa do Lago, 2007, p. 137-138).

Em síntese, pode-se dizer que, no início dos anos setenta, o Itamaraty via-se diante de pressões internacionais em prol da democracia, dos direitos humanos e do meio ambiente. Em relação a esse último, a vinculação do tema a um "discurso agressivamente reformador e desafiador" da ordem econômica internacional vigente permitia à chancelaria brasileira neutralizar, em parte, essas pressões (Corrêa do Lago, 2007, p. 141-142).

Como salienta Lílian Duarte, não obstante, "[e]m Estocolmo, o Brasil foi atacado e procurou defender seus argumentos e posições por vezes altamente polêmicos" (Duarte, 2003, p. 9). Apoiando-se no conceito de soberania absoluta, o país "apregoava ser necessário primeiro desenvolver-se, depois 'pagar a conta' dos danos ambientais, tal como haviam feito os países ricos" (Duarte, 2003, p. 17).

Em todo caso, em junho de 1972, o Brasil compareceu à Conferência de Estocolmo, ainda que com a principal intenção de se defender. De fato, o Brasil foi ator decisivo para explicitar as divergências que opunham, em Estocolmo, Norte e Sul. Demonstrando atitude combativa, a delegação brasileira defendeu, intransigentemente, o princípio da soberania nacional absoluta, criticando a obstrução da cooperação internacional por meio de mecanismos internacionais "destinados a limitar a individualidade dos Estados" e denunciando "a tentativa de subordinar a soberania aos interesses dos Estados desenvolvidos" (Duarte, 2003, p. 1718).

Quanto aos interesses dos países em desenvolvimento, a diplomacia brasileira procurou associar a degradação ambiental à pobreza, sendo a primeira como resultante desta última, manifestando-se em fenômenos 
como favelas e queimadas. Assim, a principal responsabilidade dos países em desenvolvimento seria a de se desenvolver, pois o crescimento econômico permitiria eliminar a poluição da pobreza relacionada a atividades tais como o desmatamento e o garimpo ilegal e corrigir, com uma parcela dos recursos, a poluição da afluência aquela oriunda do modo de vida baseado no consumismo das sociedades modernas. Deriva do mesmo raciocínio a posição de que gastos com meio ambiente são ilegítimos, se representarem desvio de fundos previamente destinados ao crescimento econômico. Conforme salienta Lílian Duarte: "[a] argumentação é importante porque resume também a visão do Terceiro Mundo, o que colocou o Brasil em posição de liderança dos discursos sobre desenvolvimento" (Duarte, 2003, p. 18-19).

Do mesmo modo, China e Índia, países cuja economia crescia vertiginosamente a exemplo do "milagre" brasileiro, foram aliados estratégicos para a argumentação brasileira em Estocolmo. Não por coincidência, é atribuída à então primeira-ministra indiana, Indira Gandhi, a expressão "poluição da pobreza", exaustivamente repetida pela delegação brasileira e até hoje vigente no vocabulário de formuladores de políticas ambientais nacionais. Assim, como acabou verificando-se posteriormente, a Conferência das Nações Unidas sobre Meio Ambiente Humano, inicialmente convocada pelos países desenvolvidos para tratar essencialmente da poluição, da degradação dos recursos naturais e das perspectivas de superpopulação, teria sua agenda dilatada para incluir assuntos como erosão do solo, gerenciamento de ecossistemas, desertificação e assentamentos humanos - esses últimos, todos de interesse dos países em desenvolvimento (Duarte, 2003, p. 17-19).

Se até aqui, a diplomacia combativa adotada pelo Brasil saiu-se aparentemente bem-sucedida da Conferência, foi nos últimos dias do evento, contudo, que o Brasil receberia as acusações mais fortes, "inclusive as primeiras referências ao país como vilão ambiental" (Duarte, 2003, p. 9). 0 estopim para o acirramento das tensões talvez tenha sido uma matéria publicada em um jornal sueco, declarando ser inadmissível o Brasil devastar a Amazônia, floresta "responsável por um 
terço do oxigênio do planeta". A réplica soberanista de Costa Cavalcanti, general que acompanhava a delegação brasileira, contribui para aprofundar ainda mais o impasse, ao afirmar que "o problema da integração e da ocupação da Amazônia era brasileiro e de ninguém mais" (Duarte, 2003, p. 20) e que o Brasil "não podia dar-se ao luxo de investir dinheiro na limpeza do meio ambiente" (Marcovitch, 2007).

Por fim, a Declaração de Estocolmo acabaria por refletir de forma evidente a clivagem gerada entre países desenvolvidos e em desenvolvimento no tocante ao meio ambiente, bem como a oportunidade, representada pela Conferência, para que os últimos firmassem suas posições em um contexto de singular articulação do Terceiro Mundo. A inclusão de princípios na Declaração, a exemplo da estabilização do preço das commodities e a reafirmação do direito soberano para a definição de políticas ambientais nacionais, ou ainda, a decisão de situar a sede do Programa das Nações Unidas para o Meio Ambiente (PNUMA) em Nairóbi, no Quênia, são contabilizados como fatores que, entre outros, atestariam, segundo Lílian Duarte, a "vitória, ao menos retórica, dos países em desenvolvimento" na Conferência de Estocolmo.

Ao se "olhar e perceber" os fatos históricos narrados acima à luz do pensamento teórico de Fierke, há de atentar-se para o que a autora destaca como principal crítica ao positivismo: a atividade social não pode ser compreendida se ignorando os significados que os atores sociais atribuem as suas ações. Ora, na década de 1970, não por acaso, a comunidade internacional não compreendia a atitude do governo brasileiro nas negociações multilaterais e, por conseguinte, passou a rotulá-lo de irresponsável. Do mesmo modo, o Brasil não conseguia perceber outras motivações das pressões ambientalistas estrangeiras senão a vontade de ingerência em suas políticas internas.

0 que não se percebeu à época era que, para o governo militar, o crescimento econômico representava a base de legitimação do seu sistema político, sem o qual o regime se encontraria seriamente ameaçado. Esse erro de percepção - a comunidade internacional 
dificilmente enxergava a profundidade que a discussão adquiria para o governo brasileiro - acarretou o cenário de enfrentamento que marcou a Conferência de Estocolmo, onde houve um "sério embate de ideias $e$ interesses divergentes", conduzindo os países do Sul "a uma posição defensiva e hostil à regulação internacional das questões ambientais" (Barros-Platiau, 2006, p. 255) e transformando, finalmente, o evento em um jogo de perde ou ganha excludente, no qual somente eu ou eles poderia(m) sair vitorioso(s).

De um lado, os países desenvolvidos queriam impor um novo jogo à esfera global com regras pré-determinadas. De outro, os países em desenvolvimento radicalizavam seu discurso, obstruindo o diálogo com a defesa absoluta do princípio da soberania estatal, de modo a rechaçar quaisquer ideias de ingerência ecológica (Barros-Platiau, 2006, p. 268). Aferrando-se à regra socialmente construída da soberania irrestrita, o governo brasileiro resistia a uma tentativa de "flexibilização" de uma regra anterior, considerada básica para a existência do sistema internacional vigente 5 . Ou seja, os países desenvolvidos buscavam impor unilateralmente a adoção de novas regras ao jogo, o que, como visto, implicaria necessariamente um novo jogo; ao passo que o Brasil, por sua vez, não compreendeu essa "jogada" e não aceitou a mudança nas regras do jogo.

Por fim, os resultados de Estocolmo revelariam, grosso modo, que ambos os jogadores sairiam derrotados: a comunidade internacional, frustrada em sua tentativa de avançar uma agenda ambiental, e o governo brasileiro, com uma reputação severamente desgastada.

\section{0 Rio de Janeiro e uma política externa transitiva}

Desde meados da década de 1970 e ao longo de toda década de 1980, assistiu-se a uma intensificação das denúncias ao desmatamento da Amazônia; momento em que os países centrais conseguiam convencer a

\footnotetext{
${ }^{5}$ Nas palavras de Ana Flávia Barros-Platiau: “Em fato, o princípio da soberania é o pilar do direito internacional, e, portanto, um dos mais antigos princípios reconhecidos pela comunidade internacional” (Barros-Platiau, 2006, p. 268).
} 
sociedade civil internacional de que o principal desafio ambiental global residia na tentativa de alterar a política ambiental brasileira, removendo assim as atenções sobre o excesso de consumo de combustíveis fósseis nos países do Norte (Duarte, 2003, p. 30).

Como esclarece o Embaixador Luiz Felipe de Seixas Corrêa, ao passo que a agenda multilateral nas décadas de sessenta e setenta fora ocupada por assuntos de caráter reivindicatório para os países em desenvolvimento, como exemplificado pelo comércio internacional; transformações ao longo dos anos oitenta trouxeram a ascensão de novos temas - tais como direitos humanos, narcotráfico e meio ambiente -, "cuja manipulação colocaria precisamente os países em desenvolvimento na defensiva". Esses temas despertaram, ademais, interesse crescente na opinião pública tanto dos países desenvolvidos quanto dos em desenvolvimento, o que passou adicionalmente a contribuir para a transformação qualitativa da agenda internacional (Seixas Corrêa, 2006, p. 479-480).

Em 1987, uma comissão de especialistas convocada há quatro anos pelas Nações Unidas e presidida pela então primeira-ministra norueguesa, Gro Harlem Brundtland, para propor novos rumos à gestão ambiental produziu o Relatório Nosso Futuro Comum. Segundo o Embaixador Luiz Filipe de Macedo Soares, a vasta popularidade do Relatório Brundtland inaugurou uma "segunda onda do meio ambiente", na qual não mais a poluição - satisfatoriamente relativizada nos países desenvolvidos - era o foco das discussões mas, em seu lugar, a mudança do clima e a perda de biodiversidade.

Nesse contexto, uma "série de acontecimentos fez de 1988 o ano em que o Brasil se tornou o foco principal do debate ambiental internacional" (Corrêa do Lago, 2007, p. 147). Somando-se às pressões de ordem econômica e comercial, que vinha sofrendo o Brasil devido à condição de insolvência da sua dívida externa, articulou-se na Europa Ocidental e nos Estados Unidos "verdadeira mobilização", que se apoiava em crescentes pressões advindas da sociedade civil internacional, para combater a política do governo brasileiro na Amazônia (Seixas Corrêa, 
2007, p. 501). Com efeito, haja vista a aceleração do desmatamento da floresta amazônica nos anos de 1987 e 1988, a comunidade internacional apontava, uníssona, o Brasil como "vilão" ambiental. 0 desprestígio do país na área ambiental revestia-se de tamanha importância que ofuscava a boa impressão causada pela redemocratização e chegava, até mesmo, a afetar os interesses nacionais em outros temas, a exemplo "[d]as relações do país com organismos financeiros como o Banco Interamericano e o Banco Mundial" (Seixas Corrêa, 2006, p. 476; 496) - fato que se tornava singularmente grave em contexto de crise econômica e anúncio, em fevereiro de 1987, de moratória da dívida externa. Tal campanha internacional encontraria sinergia no plano interno quando, no escopo do processo de redemocratização política, a sociedade civil brasileira passou a se organizar para defender causas ambientais específicas, como a Mata Atlântica, a Jureia e a Amazônia.

Ora, o governo de José Sarney originava-se "de um processo de transformação política e institucional orientado para a recuperação das franquias democráticas no Brasil". Doravante, seria natural ao país que, ao buscar nova identidade, "privilegiasse acima de tudo a sua essência democrática". Assim, parafraseando Gelson Fonseca Jr., com vistas ao anseio por renovar suas credenciais frente à comunidade internacional, o Brasil sentiria necessariamente obrigação de remover um legado diplomático de décadas anteriores, herdado do "entulho" autoritário.

A redemocratização do país forneceria, assim, a linha inicial de atuação externa do governo. Tanto no seu discurso diplomático, quanto na aplicação de sua política regional e multilateral, o Presidente [Sarney] utilizaria os valores da democracia para sustentar princípios e objetivos de ação. Por esta via, tornou-se possível superar a desconfiança dos anos de preeminência militar e, bem assim, desimpedir alguns canais de comunicação com o mundo desenvolvido. (Seixas Corrêa, 2006, p. 481)

Indubitavelmente, o tema do meio ambiente foi um desses canais a que faz alusão Seixas Corrêa. A partir de meados dos anos 1980, fica evidente o fato de que "[a] democracia, ao dar uma identidade nova ao 
país, tornou-o mais permeável às pressões e contrapressões internas $e$ internacionais desencadeadas no período" (Seixas Corrêa, 2006, p. 476).

Em face dessa conjuntura e da simultaneidade de pressões crescentes, internas e externas, o governo brasileiro reagiria, portanto, de modo a compatibilizar seu permanente objetivo de desenvolvimento com conservação ambiental. Seixas Corrêa elenca para tanto algumas medidas adotadas então pelo Brasil para adaptar, às prioridades nacionais, as exigências que se lhe impunham. Uma delas representaria a tomada de consciência de que o modelo de desenvolvimento herdado dos países industrializados afetaria irremediavelmente o meio ambiente e seria, pois, vantajoso evitar seus custos o quanto antes. Uma segunda medida seria a de estabelecer uma relação bitransitiva de causa e efeito entre pobreza e degradação ambiental. Uma outra consistiria simplesmente em reconhecer a existência de uma responsabilidade perante o mundo quanto à necessidade de se preservar a Amazônia, mostrando disposição inclusive de se abrir ao diálogo com a cooperação internacional e as organizações internacionais. Um quarto passo agruparia a adoção de medidas concretas para controlar o desmatamento como: o abandono dos subsídios para a agropecuária extensiva na Amazônia, a proibição do uso do mercúrio nos garimpos, a adoção de mecanismos mais eficazes de controle da exploração madeireira e o lançamento do Programa Nossa Natureza.

Dois meses depois, no dia 6 de dezembro de 1988, o Representante Permanente junto às Nações Unidas, Embaixador Paulo Nogueira Batista, apresentava a candidatura brasileira para sediar a planejada Conferência de 1992 sobre questões ambientais. Partia do Ministério das Relações Exteriores a ideia de sediar a Conferência, como forma de reverter a preocupante deterioração da imagem do país, apesar dos esforços empreendidos pelo mesmo em seu processo de redemocratização (Corrêa do Lago, 2007, p. 150-151). Como sugere Seixas Corrêa, entre todas as medidas anunciadas pelo governo Sarney, a proposta de sediar a Conferência de 1992 destacava-se como "formasíntese" da nova imagem a que aspirava o país (Seixas Corrêa, 2006, p. 
496-497).

No entanto, transcorridos apenas quinze dias após o pronunciamento da candidatura do Brasil, Chico Mendes é assassinado no Acre. A morte do líder seringueiro, que já havia recebido um dos mais prestigiosos prêmios ambientais, o Global 500, concedido pelo PNUMA, gerou ampla repercussão internacional, sendo enfocada pela mídia internacional nos mais diversos ângulos comumente aplicados ao Brasil: "violência, meio ambiente, direitos humanos, trabalhadores rurais, latifundiários, sindicalismo, impunidade". Além disso, o incidente desmoralizava o recém-criado Programa Nossa Natureza, "principalmente no tocante ao objetivo de 'proteger [...] as populações envolvidas nos processos extrativistas'”.

No início do ano seguinte, seriam renovados esforços do governo brasileiro com vistas à proteção ambiental. Criou-se assim o Instituto Brasileiro de Meio Ambiente e dos Recursos Naturais Renováveis (IBAMA), substituindo e centralizando as funções de quatro órgãos - o Instituto Brasileiro de Desenvolvimento Florestal, a Secretaria Especial do Meio Ambiente, a Superintendência de Desenvolvimento da Pesca e a Superintendência do Desenvolvimento da Heveicultura - em uma tentativa de demonstrar o tema ambiental como uma das prioridades do governo (Corrêa do Lago, 2007, p. 150-151).

Para Corrêa do Lago, essas mudanças, bem como o pleito para abrigar a Conferência de 1992, não assumiam de modo algum alinhamento às prioridades dos países desenvolvidos, mas eram sim motivadas "muito mais pelas circunstâncias internas, em função da redemocratização e da nova Constituição", tendo sido o desprezo pelo meio ambiente associado à ditadura militar (Corrêa do Lago, 2007, p. 153; 158). De fato, a Constituição de 1988 elencava a defesa do meio ambiente como um dos nove princípios gerais da atividade econômica, além de conter um capítulo inteiro sobre o meio ambiente (Artigo 225) (Corrêa do Lago, 2007, p. 146).

Seixas Corrêa, entretanto, embora admitindo a concomitância de 
pressões internas e externas para que o governo brasileiro alterasse seu posicionamento em relação ao temário ambiental, parece privilegiar as segundas.

Sobre essa agenda, o governo civil teve de operar, adaptando a diplomacia brasileira naquelas áreas em que por injunções internas, o Brasil se conteve dentro de limites artificiais, ou nas quais, por injunções externas, foi obrigado a abrir novas frentes de negociação e defesa dos interesses nacionais, como na questão do meio ambiente". [grifo meu] (Seixas Corrêa, 2006, p. 498)

De fato, ao passo que o Brasil já se havia candidatado a sediar a Conferência de 1992, repercutia no cenário internacional a ideia de se estender o conceito de direito de ingerência, cunhado inicialmente para o direito humanitário por Bernard Kouchner e Mario Bettati, a questões ambientais. Nesse contexto, o caso da Amazônia era emblemático, ganhando notoriedade sob o mito de pulmão do mundo (Corrêa do Lago, 2007, p. 155-156). Por isso, como lembra Fabio Feldman, Deputado Federal e um dos principais articuladores para a inclusão do meio ambiente na nova Constituição,

apesar da disposição de membros do Governo Sarney de alterar o discurso brasileiro, a atitude defensiva e 'soberanista' reaparecia na medida em que as discussões punham em questão a capacidade de enfrentar o desafio de proteger o patrimônio ambiental. (Corrêa do Lago, 2007, p. 157)

Em todo caso, ficaria patente, entretanto, a impossibilidade de o governo brasileiro continuar a negligenciar as questões sobre o assunto que mais despertava interesse pelo país no exterior. Assim, apesar da centralidade atribuída por Corrêa do Lago à reação da sociedade civil brasileira à transparência promovida pelo governo no processo de redemocratização política, o mesmo autor reconhece que as "pressões externas tiveram forte influência" na mudança de discurso do país no tocante à agenda ambiental. Dessa forma, em março de 1991, já sob a presidência de Fernando Collor de Mello, o então Chanceler, Francisco Rezek, declarava que 
não pretendemos, e isso deve ficar muito claro, fugir das responsabilidades que nos cabem no tocante à manutenção do equilíbrio ambiental planetário. Estamos dispostos, para essa finalidade, a trabalhar intensamente com os países de todas as outras regiões em busca de soluções para os grandes problemas que afetam o meio ambiente global. (Corrêa do Lago, 2007, p. 157-158)

Condizente com a posição supracitada, durante todo o período preparatório da Conferência, o Brasil adotou atitude de liderança totalmente distinta da assumida em Estocolmo, de vez que a convocação da Conferência de 1992 preservara os princípios centrais defendidos pelo Brasil em 1972 (Corrêa do Lago, 2007, p. 161). Para o governo brasileiro, sediar o evento representava não somente uma manobra para angariar prestígio internacional - esperava-se que fosse a maior conferência do século XX -, mas, sobretudo, a decisão consistia, nas palavras de Seixas Corrêa, em evolução da diplomacia brasileira "de uma postura defensiva para uma posição aberta e transitiva, adquirindo o Brasil credenciais de interlocutor essencial no encaminhamento multilateral das questões ambientais" (Seixas Corrêa, 2007, p. 502).

A partir de então, o discurso brasileiro acerca do meio ambiente não se limitaria apenas à tônica soberanista, mas passaria a revelar a aceitação de uma "dupla ótica", ao incorporar também uma abertura à cooperação. É essa transição da política externa brasileira quanto às negociações ambientais que simboliza a proposta de sediar a conferência de 1992 (Seixas Corrêa, 2007, p. 503).

A inflexão progressiva do discurso brasileiro em relação ao meio ambiente fez-se presente, aliás, não somente no oferecimento de sediar o evento de 1992, mas em cada alusão ao tema feita pelo presidente José Sarney, quando do seu discurso de abertura da XLIV Sessão Ordinária da Assembleia Geral da Organização das Nações Unidas, em 1989. Com efeito, por um lado, reitera-se o direito soberano "[e]stamos dispostos, como sempre estivemos, à cooperação. Contudo, nunca a imposições que atinjam nossa soberania" (Seixas Corrêa, 2007, p. 512). Porém, por outro, conforme os trechos destacados abaixo 
denotam, o discurso brasileiro passa a tratar do meio ambiente também de forma afirmativa e solidária, concebendo-o como tema prioritário e de interesse mundial.

Duas grandes questões devem igualmente ser objeto de nossa preocupação prioritária: a proteção ambiental e o combate ao tráfico e uso de drogas.

Estes temas estarão cada vez mais presentes em nossa agenda. 0 primeiro é o da sobrevivência da humanidade, a morte da vida no planeta. (Seixas Corrêa, 2007, p. 510)

Ou ainda: "[n]a questão do meio ambiente temos outra dimensão da interdependência entre as Nações. Habitantes de um mesmo e pequeno planeta, estamos condenados à solidariedade" (Seixas Corrêa, 2007, p. 511).

$\mathrm{Na}$ ocasião, outro aspecto que merece ser ressaltado no discurso do presidente brasileiro é a tentativa explícita de se contornar o impasse gerado entre países desenvolvidos e em desenvolvimento, quanto as suas percepções a respeito dos problemas ambientais.

A questão ambiental nos seus aspectos planetários - mudança do clima, destruição da camada de ozônio - não pode nem deve ser discutida de uma perspectiva estreita, como se fosse um problema Norte-Sul, em que os países menos desenvolvidos estivessem, por um comportamento irresponsável, afetando o equilíbrio ecológico mundial. (Seixas Corrêa, 2007, p. 511)

A mesma progressão do discurso diplomático brasileiro sobre o meio ambiente é acompanhada no ano seguinte, já na presidência de Fernando Collor (Hirst; Pinheiro, 1995, p. 6). Segundo Seixas Corrêa, o conceito de modernização foi visto como alavanca para operar uma transposição de rumo da atuação diplomática brasileira, de forma a recuperar um diálogo com os países desenvolvidos, julgado comprometido pelo abono, durante os últimos anos, de um viés terceiro-mundista. Ao lado de outros temas de alcance global, como não proliferação e direitos humanos, o meio ambiente também foi alvo desse esforço de modernização da posição diplomática brasileira, tendo presenciado a evolução de "padrões excessivamente rígidos $e$ 
protecionistas para atitudes mais transitivas de cooperação internacional" (Seixas Corrêa, 2007, p. 517).

Novamente, em 1991, às vésperas da realização da Conferência do Rio, o presidente Collor consagra boa parcela do seu discurso na Assembleia Geral das Nações Unidas ao tema ambiental. Em tal oportunidade, o presidente enuncia a frase que, segundo Seixas Corrêa, tornaria-se célebre no contexto da Conferência, sendo frequentemente citada por sintetizar a inter-relação entre meio ambiente e desenvolvimento: "(...) [n] ão podemos ter um planeta ambientalmente sadio num mundo socialmente injusto" (Seixas Corrêa, 2007, p. 517).

Em 1992, ocorre portanto a Conferência do Rio, despontando-se como o maior evento organizado pelas Nações Unidas até aquele momento, reunindo delegações de 172 países e 108 chefes de Estado ou de Governo. Ao longo do encontro, o fator que maiores dificuldades provocou foi a percepção do peso que representariam as medidas visando desacelerar o processo de aquecimento global.

As divergências só seriam supridas com o enfraquecimento do teor normativo do texto final em discussão. A solução escolhida foi de não mencionar metas específicas para, ao menos, assegurar o reconhecimento consensual da necessidade de se reduzir as emissões de gases de efeito estufa. Assim, o impasse esquivado na ConvençãoQuadro sobre Mudança do Clima assinada no Rio de Janeiro, que contou inclusive com a ratificação norte-americana, foi apenas adiado, já ressurgindo vigorosamente cinco anos depois, quando das negociações para o Protocolo de Quioto (Corrêa do Lago, 2007, p. 73-74).

De forma esclarecedora, Corrêa do Lago sugere o seguinte balanço da Conferência de 1992:

[a] avaliação mais correta da Conferência do Rio talvez tenha sido dada pela própria agenda da Cúpula de Joanesburgo: não se deve questionar nem corrigir o legado do Rio; deve-se melhorar e fortalecer os instrumentos que tornem possível a implementação mais efetiva de seus resultados. (Corrêa do 
Lago, 2007, p. 86)

Ademais, se o Relatório Brundtland consolidou o conceito de desenvolvimento sustentável, pode-se dizer que foi a Conferência de 1992 que popularizou definitivamente o termo. Com efeito, reiterando a necessidade de conciliar-se progresso econômico e respeito ao meio ambiente, ao final do evento, foram aprovadas a Convenção sobre Mudanças Climáticas, a Convenção sobre Diversidade Biológica, a Declaração sobre Manejo das Florestas, a Declaração do Rio e a Agenda 21, sendo essa última um programa de ação reunindo as recomendações práticas das decisões alcançadas na conferência. Mas, apesar do resultado final aparentemente promissor, a conferência foi marcada por intensos debates, chegando-se a acreditar por vezes que o evento terminaria sem acordo algum. Em especial, cabe ressaltar as fortes críticas feitas ao presidente dos Estados Unidos, George Bush, tendo em vista que as posições da delegação norte-americana refletiam retrocessos em praticamente todas as áreas discutidas (Duarte, 2003, p. 42).

Já para o Brasil, a Conferência do Rio logrou plenamente as expectativas e os objetivos, consagrando-se como marco das relações multilaterais e êxito diplomático do país. Ademais, "ironicamente, os cartazes de protesto identificavam não mais o Brasil como o vilão ambiental, mas os Estados Unidos", percepção essa até hoje vigente (Duarte, 2003, p. 43).

A partir de 1992, o Brasil passa a postular o cumprimento dos compromissos acordados na Conferência do Rio, "cuja repercussão extraordinariamente positiva no âmbito externo oferecia ao país a possibilidade de exercer uma política externa pragmática voltada para ganhos concretos" (Duarte, 2003, p. 53).

Em 1992, a poucos dias do impeachment do presidente Fernando Collor, e já tendo ocorrido exitosamente a Conferência do Rio de Janeiro, o ministro das Relações Exteriores, Celso Lafer, incorporava a agenda ambiental como um dos pilares do seu discurso na Assembleia Geral da ONU. Ressaltando o sucesso das negociações obtidas no Rio de Janeiro, 
o ministro destacou o evento como instaurador de um "novo paradigma, um novo contrato social", erigidos sobre o conceito fundamental do desenvolvimento sustentável, o qual realocava as relações Norte-Sul "sob o signo da cooperação" (Seixas Corrêa, 2007, p. 560; LAFER, 1993, p. 276).

Evidencia-se, portanto, o ponto de inflexão simbolizado pela Conferência do Rio para a política externa brasileira acerca da agenda ambiental internacional. Em entrevista concedida aos pesquisadores Paulo S. Wrobel e Alexandra de Mello e Silva, Celso Lafer afirmou, após constatar a perspectiva defensiva do discurso diplomático brasileiro, que

alterei a postura de negociação do Brasil. Porque cheguei à seguinte conclusão: o Brasil é o país-sede, cabe-lhe portanto ter uma posição de catalisador do consenso. [...] Logo, cabe ao Brasil uma postura que deve transcender os nossos interesses específicos e incluí-los dentro dos marcos de uma visão geral. (Lafer, 1993, p. 275)

Alteração, essa, que segundo o Embaixador Seixas Corrêa contou com a seguinte repercussão: "[c]om o oferecimento feito no governo Sarney $e$ posterior realização da Conferência no Rio de Janeiro, o Brasil abriu um capítulo novo em sua diplomacia" (Seixas Corrêa, 2006, p. 497).

Essa nova fase captada pelo autor, ou ainda, esse "esverdeamento' da soberania" (Barros-Platiau, 2006, p. 269) podem ser entendidos à luz da teoria exposta por Fierke como uma mudança de regras, que passou a alterar o "jogo" no qual se estabeleciam os vínculos entre os atores sociais. De fato, segundo Pedro Motta Pinto Coelho, na prática, a "identidade fundamental entre meio ambiente e desenvolvimento se traduziu, no Rio, por uma 'barganha entre o Sul e o Norte'” (Coelho, 1994, p. 237). No novo "jogo", muda-se o status do "jogador" Brasil que, de vilão, começa a ser encarado como mocinho. De fato, com a consolidação do paradigma do desenvolvimento sustentável, a "regra" desenvolvimento é acatada consensualmente pelos atores sociais como premissa para se abordar a agenda ambiental. Nesse novo "jogo" - pois, 
como lembra Fierke, toda alteração de regras implica necessariamente mudança de jogo -, é possível observar um deslocamento qualitativo no contrato social entre países desenvolvidos e em desenvolvimento, uma vez que, ao invés das acusações mútuas que caracterizaram o diálogo em Estocolmo, não mais se procurou apontar culpados, mas, ao contrário, encontrar uma forma de socializar as responsabilidades. Desse modo, deixa de fazer sentido, para o Brasil, ostentar posição combativa e excessivamente reivindicatória. Ou ainda, sempre nas palavras de Seixas Corrêa, "[a]o evoluir de uma postura defensiva para uma posição aberta e construtiva, o país adquiria condição de interlocutor de primeira importância em matéria ambiental" (Seixas Corrêa, 2006, p. 497).

Essa transmutação expressar-se-ia com tamanha evidência que, até mesmo antes da realização da Conferência no Rio, ainda ao final da presidência de Sarney, as preocupações ambientais internacionais concernentes ao Brasil "já estavam colocadas dentro de certas balizas e devidamente relativizadas" (Seixas Corrêa, 2006, p. 497).

Por fim, analisando os resultados da Conferência das Nações Unidas sobre Meio Ambiente e Desenvolvimento, o secretário-geral da organização, Boutros Boutros-Ghali, vislumbrou o surgimento de um novo contrato social a moldar as relações internacionais em fins do século passado, o qual consagraria sob a expressão de Espírito do Rio (Coelho, 1994, p. 235).

\section{Joanesburgo e uma diplomacia afirmativa}

Para a socióloga Samyra Crespo, no que diz respeito à consciência ambiental, o Brasil "nunca foi o mesmo depois da Rio-92" (Crespo, 2003, p. 63). No decorrer da década que separou as duas conferências do Rio de Janeiro e de Joanesburgo, é possível apontar, como principal legado do período no Brasil, o fortalecimento da sociedade civil, que participou ativamente do impeachment do presidente Collor e que viveu a inauguração de uma estabilidade econômica desconhecida ao longo de toda a segunda metade do século XX. Acompanhando de forma correlata 
esse fenômeno, viu-se igualmente, nesse momento, que a intensificação da vida política democrática possibilitou a valorização da temática ambiental na agenda pública do país. Articulando-se de forma crescente, as organizações da sociedade civil passaram, gradativamente, a influenciar a posição brasileira sobre o tema, como atesta a realização do Fórum Brasileiro sobre Mudanças Climáticas (Barros-Platiau, 2006, p. 274-275).

Descrevendo a transformação da política ambiental brasileira como uma consequência situada a meio caminho entre inferências externas e internas, Pedro Motta Pinto Coelho propõe ademais que, a exemplo do que ocorreu no Brasil, "os movimentos de democratização em diversos países em desenvolvimento" ensejaram

maior conscientização, pelas respectivas sociedades, da questão ambiental, contribuindo para legitimá-la dentro de um quantum de tempo muito menor do que o utilizado pelas sociedades já desenvolvidas. (Coelho, 1994, p. 235)

Enquanto se transcorria o processo preparatório para o encontro em Joanesburgo, o Ministério do Meio Ambiente manifestava preocupação com o que julgava ser uma centralização das questões africanas e da pobreza no foco da Cúpula. Como lembra Lílian Duarte, o fato de o Brasil declarar que o tema da pobreza não deveria ser manipulado, para ofuscar a percepção do agravamento dos problemas ambientais planetários, representava inflexão significativa da diplomacia brasileira com relação a Estocolmo, momento em que "o país afirmava em tom contundente que a verdadeira poluição era a pobreza" (Duarte, 2003, p. 54). Em 2002, a intenção brasileira era a de que não fossem renegociados temas pertencentes ao Legado do Rio, como passou a ser conhecido o conjunto de acordos e propósitos alcançados em 1992 (Duarte, 2003, p. 55).

No objetivo de angariar maior visibilidade às prioridades nacionais para o tema, o governo brasileiro formalizou, em maio de 2002, a Iniciativa Latino-Americana e Caribenha para o Desenvolvimento Sustentável (ILAC), aprovada unanimemente pelos ministros do meio 
ambiente da região e que incorporava a proposta brasileira de energia, elaborada pelo professor José Goldemberg, segundo a qual se previa a adoção de uma matriz energética de pelo menos $10 \%$ de fontes renováveis até 2010. 0 franco apoio regional, obtido pelo Brasil poucos meses antes, possibilitaria ao país exercer notória liderança na área de energias renováveis durante toda Cúpula de Joanesburgo, quando o país transpôs a proposta regional para o âmbito global (Corrêa do Lago, 2007, p. 172-173).

Na ocasião, em uma visível transformação das posições adotadas nas Conferências anteriores, sobretudo em relação à de Estocolmo, nas palavras da ex-ministra Marina Silva, o Brasil desempenhou "firme posição protagonista" e "destacou-se nas tentativas de superação dos impasses regionais e internacionais que impediam o progresso das negociações" (Corrêa do Lago, 2007, p. 173).

A delegação brasileira atuou, durante as sessões do Comitê Preparatório e na própria Cúpula, conforme determinação de que os membros do Grupo dos 77 e China tomariam decisões por consenso, após reuniões internas. Se o mecanismo permitiu a adoção de posições conjuntas, as negociações acerca das energias renováveis dividiram o bloco, assim como ocorrera entre os países desenvolvidos. De um lado, a União Européia e a América Latina e Caribe formaram uma frente, para que fosse incorporada ao Plano de Implementação de Joanesburgo uma meta percentual de fontes renováveis na matriz do consumo energético mundial. De outro lado, Estados Unidos e os principais países produtores de petróleo impuseram uma série de obstáculos à proposta, mas não conseguiram impedir, contudo, a inclusão no texto final de diversas referências às mudanças necessárias quanto às energias renováveis, inclusive uma recomendação de caráter urgente no sentido de aumentar consideravelmente a participação global das fontes de energia renovável.

Destacou-se ainda o Brasil na liderança da posição do G-77 e China nas seções sobre biodiversidade e meios de implementação. Na primeira, como porta-voz do grupo, o país logrou importante resultado, no 
contexto da Convenção sobre diversidade biológica, com o lançamento das negociações de um instrumento internacional sobre a repartição dos benefícios derivados da utilização de recursos genéticos. Em relação aos meios de implementação, passaria a ser lembrado pelas organizações não governamentais, como uma das maiores vitórias da Cúpula, a aprovação de um parágrafo sobre responsabilidade corporativa e accountability, que se baseava na argumentação brasileira e sofrera resistências dos Estados Unidos até a última hora (Corrêa do Lago, 2007, p. 176).

Ao final da Cúpula, embora reconhecendo certa frustração perante os resultados obtidos, a Delegação brasileira registrava como êxito o endosso de princípios firmados na Conferência do Rio, como atesta o da responsabilidade comum mas diferenciada para os países desenvolvidos e em desenvolvimento. 0 tratamento da biodiversidade foi outro aspecto que satisfez os diplomatas brasileiros, haja vista que um acordo sobre megadiversidade fora firmado por quinze países, incluindo o Brasil, com o objetivo de reduzir significativamente as taxas de extinção de animais e plantas raros até 2010, além de assegurar que as comunidades locais participem dos benefícios oriundos da exploração de recursos naturais situados em suas terras.

Dessa forma, Lílian Duarte aventa que

[m] esmo os que consideram os resultados de Joanesburgo decepcionantes reconhecem na atuação brasileira elementos de criatividade e maturidade política que podem contribuir efetivamente para os esforços globais de equacionamento da complexidade dos problemas ambientais. (Duarte, 2003, p. 910)

Ainda assim, malgrado os avanços da participação brasileira na agenda ambiental internacional, a posição do país frente ao tema ainda é passível de críticas e desconfiança. Segundo o diretor do PNUMA de Nova Iorque, Adnan Amin, a flexibilidade demonstrada pela delegação brasileira em Joanesburgo "não conseguiu esconder que as posições ainda são conservadoras". Além disso, na opinião do mesmo, iniciativas 
"propositivas" do Brasil, como o caso das energias renováveis, não são orientadas por princípio, mas tão somente pela situação confortável do país nessas áreas (Corrêa do Lago, 2007, p. 178).

Embora não satisfaça a todos, é inegável, entretanto, a observância de progressos na tônica diplomática brasileira acerca da agenda ambiental internacional, sobretudo se forem confrontadas as posições advogadas em Estocolmo e Joanesburgo. Como visto, se na década de 1970, o Brasil revelou-se ator reativo, por ter sido apontado como mau "jogador", e combativo, por discordar à época das regras do "jogo"; em Joanesburgo, já superada a etapa transitiva do Rio de Janeiro, o país despontava como "jogador" proativo e engajado em um contexto no qual as regras do "jogo" eram percebidas como suscetíveis de oferecer ganhos reais à nação. Interpretando o conceito de desenvolvimento sustentável por um viés socioambiental, a diplomacia brasileira coloca elementos de seu interesse - a exemplo da responsabilidade histórica do Norte, da erradicação da pobreza e do acesso a mercados - no cerne das questões ambientais (Barros-Platiau, 2006, p. 276). É sob essa ótica que podem ser interpretados os esforços do Brasil de se materializar as possibilidades de ganhos que se apresentavam em Joanesburgo, o que explica, em parte, as iniciativas brasileiras de se lograr um novo contrato normativo que concretizasse as aspirações contidas no Legado do Rio.

\section{Conclusão}

Além do ganho em visibilidade, o debate multilateral sobre o meio ambiente forjado no espaço "onusiano" teve por mérito explicitar o fato de que, em suma, "o desafio da sustentabilidade é um desafio eminentemente político" (Guimarães, 1994, p. 230).

Como salienta Lílian Duarte, participar da Conferência de Estocolmo foi marcante para o Brasil, pois: "[t]ornar-se vilão ambiental aos olhos da comunidade internacional foi uma experiência dramática com impacto considerável na política externa brasileira” (Duarte, 2003, p. 7). 
Alvo dos refletores internacionais, a resposta brasileira na ocasião sugeria uma intenção dos países ricos de conter o crescimento econômico nacional e de legitimar eventuais intervenções no país, para afirmar uma ordem ecológica que se constituía a despeito da objeção dos países em desenvolvimento. Essa reação do governo brasileiro, presente em parte ainda quando da transmissão da presidência da República ao vice José Sarney, explicitava a vulnerabilidade generalizada do país que atravessava, além das dificuldades inerentes à transição de regime político, uma situação de estagflação atrelada à crise da dívida externa. Internamente, a defesa soberanista da Amazônia e a correlata identificação de uma conspiração externa conseguiam, ademais, angariar base de apoio fundamental à jovem democracia, reunindo, sob o mesmo mote, de militares a comunistas. Como afirma Lílian Duarte, no entanto, as autoridades brasileiras não souberam compreender naquele momento que as pressões internacionais sobre o país representavam de fato reivindicações populares de sociedades democráticas, que atrelavam conservação ambiental a qualidade de vida - percepções estas que já ecoavam até mesmo na sociedade brasileira, enfim liberta da censura militar (Duarte, 2003, p. 32).

A oportunidade para a superação dessa turbulência na política brasileira ocorreu, ainda que tardiamente, com a realização da Conferência de 1992, no Rio de Janeiro. Antes mesmo do evento, o país já vinha tentando demonstrar gestos conciliatórios, como ilustram, entre outros, a criação de programas de conservação florestal na Amazônia e a demarcação de terras indígenas. Ao mesmo tempo, no plano externo, a tônica da diplomacia brasileira também se abrandava. À medida que a reivindicação do direito ao desenvolvimento se transmutou para o direito ao desenvolvimento sustentável, a retórica tradicional, nacionalista e soberanista, foi sendo paulatinamente substituída por apelos ao diálogo e à cooperação (Barros-Platiau, 2006, p. 251). Ter sediado a Conferência de 1992 foi "[o] coroamento dessa estratégia e ponto de partida para o aprimoramento do desempenho brasileiro nos fóruns ambientais internacionais" (Duarte, 2003, p. 8-9). 
No período entre as Conferências do Rio de Janeiro e de Joanesburgo, o Embaixador Gelson Fonseca Jr. discernia de forma minuciosa a mudança em curso que se operava na política externa brasileira como um todo.

A autonomia, hoje, não significa mais "distância" dos temas polêmicos para resguardar o país de alinhamentos indesejáveis. Ao contrário, a autonomia se traduz por "participação", por um desejo de influenciar a agenda aberta com valores que exprimem tradição diplomática e capacidade de ver os rumos da ordem internacional com olhos próprios, com perspectivas originais. (Fonseca, 1998, p. 368)

Os conceitos cunhados pelo autor encaixam-se com perfeição no contexto da diplomacia brasileira perante a agenda ambiental internacional, entre os eventos de 1972 e 2002. Se em Estocolmo o Brasil enxergava a importância de resguardar certa autonomia pela "distância", alcançada por posições defensivas e combativas, em 1992 e, mais ainda, em 2002, o país assegura sua autonomia pela "participação", pelo engajamento propositivo, ocupando espaços em foros multilaterais, influenciando o rumo das negociações internacionais e sendo, inclusive, formulador de propostas tais como mecanismos de trocas ambientais e metas de energia renovável, que se tornariam o cerne dos debates subsequentes.

Como observa Eduardo Viola, "o que realmente interessa num regime ambiental é o estabelecimento de regras de ação realistas que permitam uma negociação progressiva entre os diversos atores na procura do objetivo comum" [grifo meu] (Viola, 2003, p. 187).

Enfrentamento em Estocolmo, conciliação no Rio de Janeiro, engajamento em Joanesburgo. Com auxílio da teoria construtivista avançada por Fierke, pode-se sugerir que a mudança da posição brasileira frente ao meio ambiente é decorrente de alterações nas regras do "jogo" operadas tanto pelo "jogador" Estado brasileiro de um lado, quanto pelo "jogador" países desenvolvidos de outro. Assim, aplicando os termos teóricos de Fierke, pode-se propor que 
desenvolvimento sustentável é o nome do "jogo", no qual o "jogador" países em desenvolvimento, sob a liderança brasileira, impôs, como condição de sua participação, a "regra" desenvolvimento; ao passo que o "jogador" países desenvolvidos fixou, por sua vez, a "regra" sustentável.

Desse modo, pode-se afirmar, em síntese, que

[f]oi neste contexto de clivagem Norte-Sul que o conceito de desenvolvimento sustentável tornou-se o principal paradigma de todas as políticas ambientais estatais [em todos os países em geral], a começar, evidentemente, pelo discurso oficial. [grifos meus] (Barros-Platiau, 2006, p. 255)

Por último, nota-se ainda que, conforme sugere a teoria de Fierke, foi por meio dos recursos linguísticos, no caso empírico abordado, que cada ator social negociou sua orientação diplomática, ambas as quais, uma vez compatíveis, geraram um novo "jogo", um novo contrato social - uma nova agenda ambiental internacional.

\section{Referências Bibliográficas:}

BARROS-PLATIAU, Ana Flávia. A política externa ambiental: do desenvolvimentismo ao desenvolvimento sustentável. In: ALTEMANI; LESSA (Orgs.). Relações Internacionais do Brasil: temas e agendas. São Paulo: Saraiva, 2006. p. 251-281.

CLUB OF ROME. Disponível em: <http://www.clubofrome.org> Acesso em: 29 abr. 2009.

COELHO, Pedro Motta Pinto. O Tratamento Multilateral do Meio Ambiente: Ensaio de um novo espaço ideológico. In: FONSECA Jr., Gelson; CASTRO, Sérgio Henrique Nabuco de (Orgs). Temas de Política

Externa II. v. 1. Brasília/São Paulo: FUNAG/Paz e Terra, 1994. p. 233262.

CORREAA do LAGO, André Aranha. Estocolmo, Rio, Joanesburgo: 0 
Brasil e as Três Conferências Ambientais das Nações Unidas. Brasília: FUNAG, 2007.

CRESPO, Samyra. Uma visão sobre a evolução da consciência ambiental no Brasil nos anos 1990. In: TRIGUEIRO, André (Coord.). Meio Ambiente no Século 21: 21 especialistas falam da questão ambiental nas suas áreas de conhecimento. Rio de Janeiro: Sextante, 2003. p. 6073.

DUARTE, Lílian Cristina Burlamaqui. Política externa e meio ambiente. Rio de Janeiro: Jorge Zahar Editor, 2003.

LAFER, Celso. Entrevista com Celso Lafer. In: Estudos Históricos, v. 6. Rio de Janeiro: CPDOC, 1993. p. 271-284.

FIERKE, Karin M. Critical Methodology and Constructivism. In: FIERKE, Karin M.; JORGENSEN, Knud Erik. Constructing International Relations: the next generation. New York: M. E. Sharpe, 2001. P. 115135.

FONSECA Jr., G. Alguns Aspectos da Política Externa Brasileira Contemporânea. In: . A Legitimidade e Outras Questões

Internacionais: Poder e Ética entre as Nações. São Paulo: Paz e Terra, 1998. p. 353-374.

GUIMARÃES, Roberto P. Da Oposição entre Desenvolvimento e Meio Ambiente ao Desenvolvimento Sustentável: Uma Perspectiva do Sul. In: FONSECA Jr., Gelson; CASTRO, Sérgio Henrique Nabuco de (Orgs). Temas de Política Externa II. V. 1. Brasília/São Paulo: FUNAG/Paz e Terra, 1994. p. 201-232.

HIRST, Mônica; PINHEIRO, Letícia. A política externa do Brasil em dois tempos. Revista Brasileira de Política Internacional, ano 38, n. 1, 1995. p. 5-23.

MARCOVITCH, Jacques. Para mudar o Futuro: Mudanças Climáticas, 
Políticas Públicas e Estratégias Empresarias. São Paulo: Editora Saraiva \& Edusp, 2007.

SEIXAS CORRÊA, Luiz Felipe de (Org.). O Brasil nas Nações Unidas. Brasília: FUNAG, 2007.

A Política Externa de José Sarney. In: ALBUQUERQUE, J. A. G.; SEITEnfuS, R.; CASTRO, S. N. de. Sessenta Anos de Política Externa Brasileira (1930-1990). Volume I: Crescimento, Modernização e Política Externa. 2a ed. Rio de Janeiro: Editora Lumen Júris, 2006. p. 467-513.

VIOLA, Eduardo. As complexas negociações internacionais para atenuar as mudanças climáticas. In: TRIGUEIRO, André. Meio Ambiente no Século 21: 21 especialistas falam da questão ambiental nas suas áreas de conhecimento. Rio de Janeiro: Sextante. 2003. p. 180-197.

VIZENTINI, Paulo Fagundes. A política externa do regime militar brasileiro: Multilateralização, desenvolvimento e construção de uma potência média (1964-1985). Porto Alegre: UFRGS, 1998. 